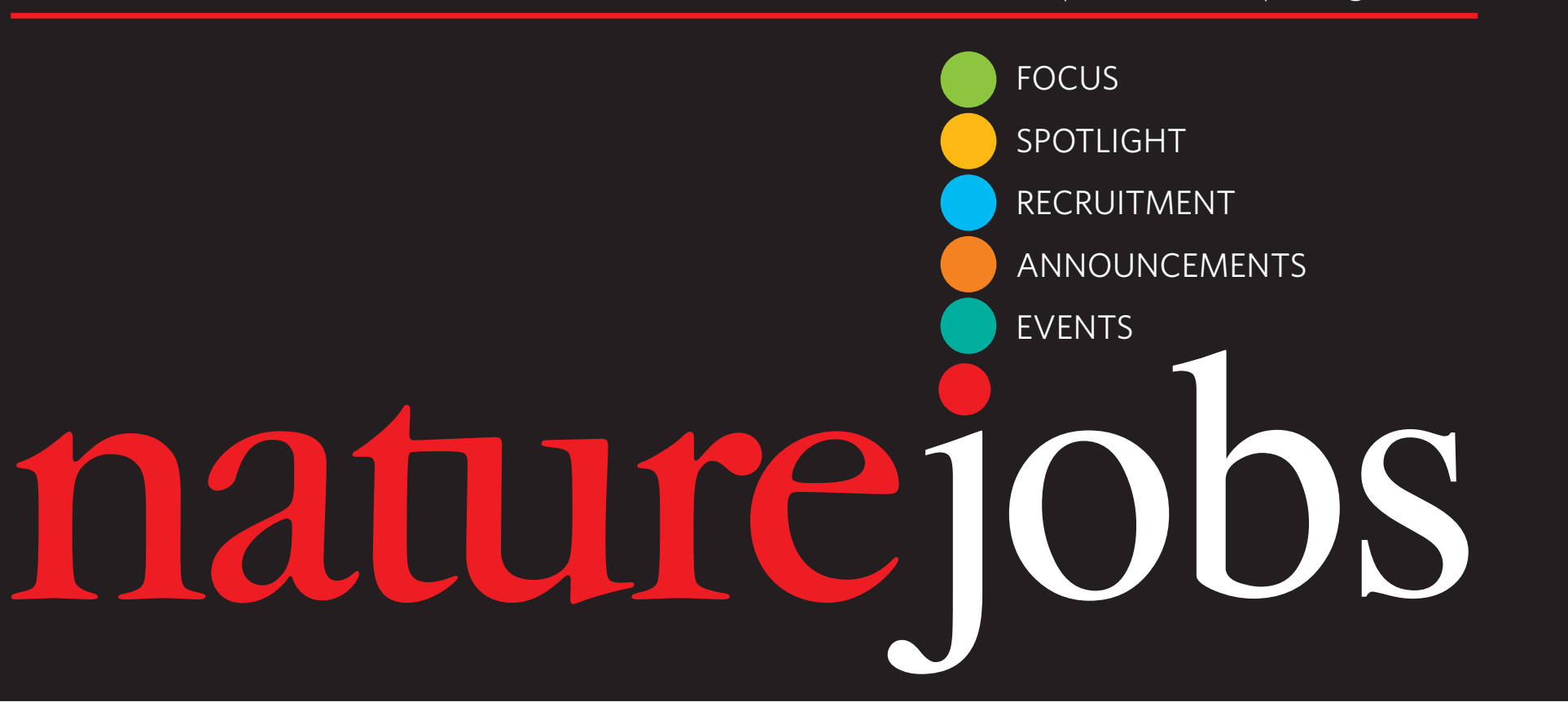

\title{
For love or money
}

A recent survey by the magazine Money confirms what many US academic scientists have always suspected.

They are indeed paid disproportionately low salaries compared with other professions, given their skills, level of education, time spent training and workload.

The survey used data from the US Bureau of Labor Statistics to weigh up various salaries and puts being an academic research scientist in with two other professions architects and chefs - that look glamorous from the outside but are less so if you're trying to make a living as one.

An assistant professor of microbiology earns $\$ 39,000$ 67,000 , according to the survey, and an entry-level medical researcher gets $\$ 35,000$. This may sound reasonable, but what makes these salaries disproportionate is the six or eight years it takes to reach PhD level - plus the subsequent years spent doing postdoctoral training, a phase that takes twice as long as it did ten years ago.

In terms of time, architects are reasonably similar to academic researchers. They spend about seven years completing undergraduate and master's degrees, then need another three years as interns working for licensed

CONTACTS

Publisher: Ben Crowe

Editor: Paul Smaglik

Marketing Manager: David Bowen

US Head Office, New York

345 Park Avenue South, 10th Floor,

New York, NY 10010-1707

Tel: +1 8009897718

Fax: +18009897103

e-mail: naturejobs@natureny.com

US Sales Manager/Corporations: Peter Bless

Classified Sales Representatives

Tel: +1800989 7718
New York/Pennsylvania/

Latin America: Kelly Roman

Midwest USA/Maryland/

NIH: Wade Tucker

East USA/Canada:

Janine Taormina

San Francisco Office

Classified Sales Representative:

Michaela Bjorkman

West USA/West Corp. Canada

225 Bush Street, Suite 1453

San Francisco, CA 94104

Tel: +14157813803

Fax: +14157813805

e-mail:m.bjorkman@naturesf.com

architects, where they'll earn about $\$ 35,000$ a year strikingly similar to the typical postdoc stipend. After three years they can take an exam to get their licence and eventually earn salaries of $\$ 60,000$ or more, equivalent to a scientist on the tenure track. But unlike scientists, architects tend to have high levels of student loans, as they don't tend to get funding during their graduate studies.

Chefs may not face such a long slog to a decent salary, but they probably face tougher day-to-day conditions. Until they make it to executive chef level, they'll earn an average of \$10-19 an hour, and will work long, hot days in the kitchen, under a lot of stress. Although a few become celebrities, with their own TV shows and lines of cookware, most do not. Like scientists and architects, they tend to work for love, not money.

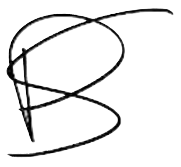

\section{Paul Smaglik, Naturejobs editor}

European Head Office, London

The Macmillan Building,

4 Crinan Street,

London N19XW, UK

Tel: +44 (0) 2078434961

Fax: +44 (0) 2078434996

e-mail: naturejobs@nature.com

Naturejobs Sales Director: Nevin Bayoumi (4978) European Sales Manager: Andy Douglas (4975)

Advertising Production Manager: Billie Franklin To send materials use London address above. Tel: +44 (0) 2078434814

Fax: +44 (0) 2078434996

e-mail: naturejobs@nature.com
Naturejobs web development: Tom Hancock Naturejobs online production: Niamh Shields

European Satellite Office

Patrick Phelan

e-mail:p.phelan@nature.com

Japan Head Office, Tokyo

Chiyoda Building,

2-37 Ichigayatamachi,

Shinjuku-ku,

Tokyo $162-0843$

Tel: +81332678751

Fax: +81332678746

Asia-Pacific Sales Director: Rinoko Asami

e-mail: r.asami@naturejpn.com 